\title{
BIOMECHANICAL ASPECTS OF THE ACHILLES TENDINOPATHY DEVELOPMENT IN RETROCALCANEAL BURSITIS AND HAGLUND SYNDROME
}

\section{Herasimyuk B. S., Lazarev I. A.}

\section{INTRODUCTION}

Retrocalcaneal bursitis (RB) is an inflammatory disease that occurs as a result of mechanical impingement of the retrocalcaneal (deep) synovial bursa located between the Achilles tendon (AT) and the posterior-superior part of the calcaneus. Haglund syndrome was described by Swedish orthopedic surgeon Patrik Haglund ${ }^{1}$ in 1928 and included the bursitis, but caused by the impingement of the synovial bursa between the AT and the enlarged posterior-superior part of the calcaneus - "Haglund deformation"2. Karjalainen, P. T., Soila, K., et al. ${ }^{3}$ in the study of 118 symptomatic tendons an enlarged retrocalcaneal bursa was diagnosed in $19 \%$ of cases. It was also found that in 15 of 18 cases of insertional tendinopathy RB was detected. Todd A. Irwin in his study ${ }^{4}$ also points to the link between inflammatory processes in the synovial bursa and the degenerative changes of the tendon itself - between RB and tendopathy. In the course of a retrospective study ${ }^{5}$ 176 patients with insertional tendopathy AT Håkan Alfredson and Christoph Spang found that $74 \%$ of patients were also diagnosed with superficial/retrocalcaneal bursitis and Haglund syndrome. Therefore, based on previous research, we can say that the relationship between RB or Haglund syndrome and tendinopathy is very likely and needs further study.

\footnotetext{
${ }^{1}$ Haglund P. Beitrag zur Klinik der Achillessehne. Zeitschr Orthop Chir. 1928. № 49. P. 49-58.

${ }^{2}$ Reinherz R.P., Smith B.A., Henning K.E. Understanding the pathologic Haglund's deformity. J Foot Surg. 1990. № 29. P. 432-435.

${ }^{3}$ Karjalainen P. T., Soila K., Aronen H. J. [et al.] MR Imaging of Overuse Injuries of the Achilles Tendon. American Journal of Roentgenology. 2000. № 175(1). P. 251-260. DOI : 10.2214/ajr.175.1.1750251.

${ }^{4}$ Irwin T. A. Current Concepts Review: Insertional Achilles Tendinopathy. Foot \& Ankle International. 2010. № 31(10). P. 933-939. DOI :10.3113/fai.2010.0933.

${ }^{5}$ Alfredson H., \& Spang C. Clinical presentation and surgical management of chronic Achilles tendon disorders - A retrospective observation on a set of consecutive patients being operated by the same orthopedic surgeon. Foot Ankle Surg. 2018 Dec. № 24(6). P. 490-494. DOI 10.1016/j.fas.2017.05.011.
} 
We believe that the study of biomechanical relationships between the structures of the normal and pathology rear foot allows you to look more broadly at the of the pathophysiology process, as well as identify key factors of pathogenesis, which can improve the effectiveness of treatment.

Modern computer simulation technologies allow us to calculate with great precision the various necessary parameters without resorting to a long, costly and difficult experiment.

\section{Methodology of biomechanical research}

The aim of this study was to determine the relationship between retrocalcaneal bursitis / Haglund syndrome and the development of secondary AT tendinopathy. Mathematical calculations and computer simulations have investigated the stress-strain state (SSS) of the rear foot structures in the act of walking and standing in RB and Haglund syndrome compared with intact foot. A scientific search in the literature did not reveal any studies of the SSS structures of the rear foot structures (AT, deep synovial bursa, calcaneus) in RB or Haglund syndrome.

Initially, for all further biomechanical calculations, a simulated 3-D solid foot model was created using the "SolidWorks" software package (Dassault Systèmes SolidWorks Corporation, Canada). The model in the neutral position in the ankle is presented in Fig. 1.

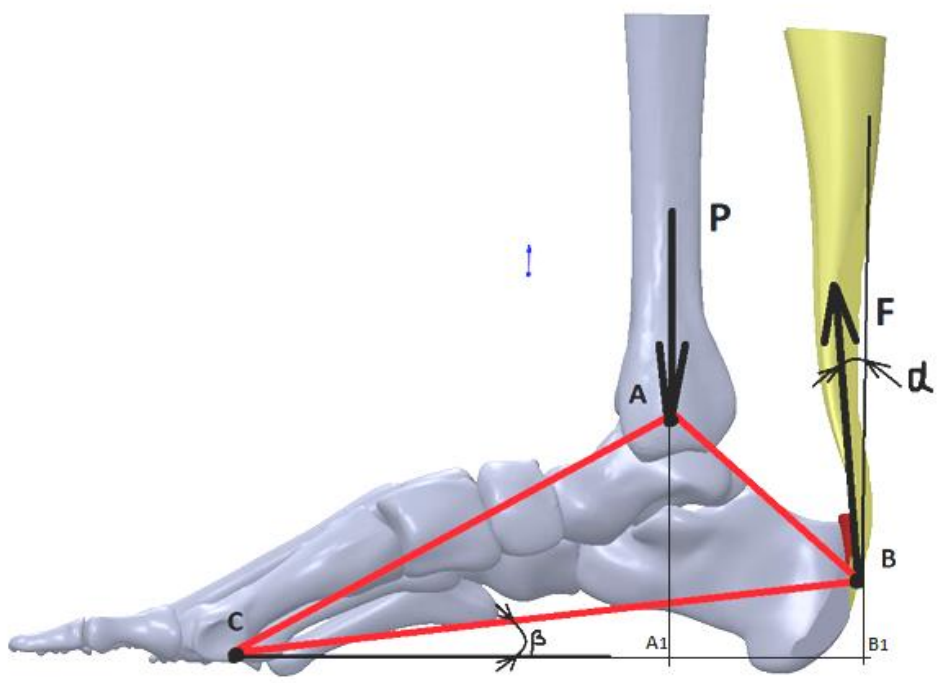

Fig. 1. 3D model in the neutral position in the ankle 
To determine the force of the calf muscle and AT in standing and walking we developed a calculation diagram (Fig. 1). The assumption is made that the value of $\mathrm{CB}_{1}$ does not change with the rotation of the foot around $\mathrm{C}$, then from the equilibrium condition:

$$
\sum M_{c}=0: F \cdot \sin \alpha \cdot C B_{1}-P \cdot C A_{1}=0 ;
$$

where $\alpha$ - the angle of inclination of the AT relative to the vertical axis; $\mathrm{P}$ - body weight $750 \mathrm{~N}$ (75 kg); F - Achilles tendon tension force.

$$
F=\frac{P \cdot C A_{1}}{\sin \alpha \cdot C B_{1}}=458 \mathrm{H} ;
$$

- the force of the calf muscle to maintain the vertical position of the body in standing.

To determine the force of tension of the AT in walking, consider 2 positions - heel strike phase of gait, on the onset of the heel of the front foot (plantar flexion $-10^{\circ}$ ) and toe-off phase of gait, when tearing off the heel of the back foot during repulsion from the ground (dorsal flexion $+10^{\circ}$ ). To achieve a plantar flexion of $-10^{\circ}$, the center of mass is shifted back to the distance $\mathrm{AB}$ as shown in Fig. 2. Therefore, this distance must be taken into account for calculations of the AT tension.

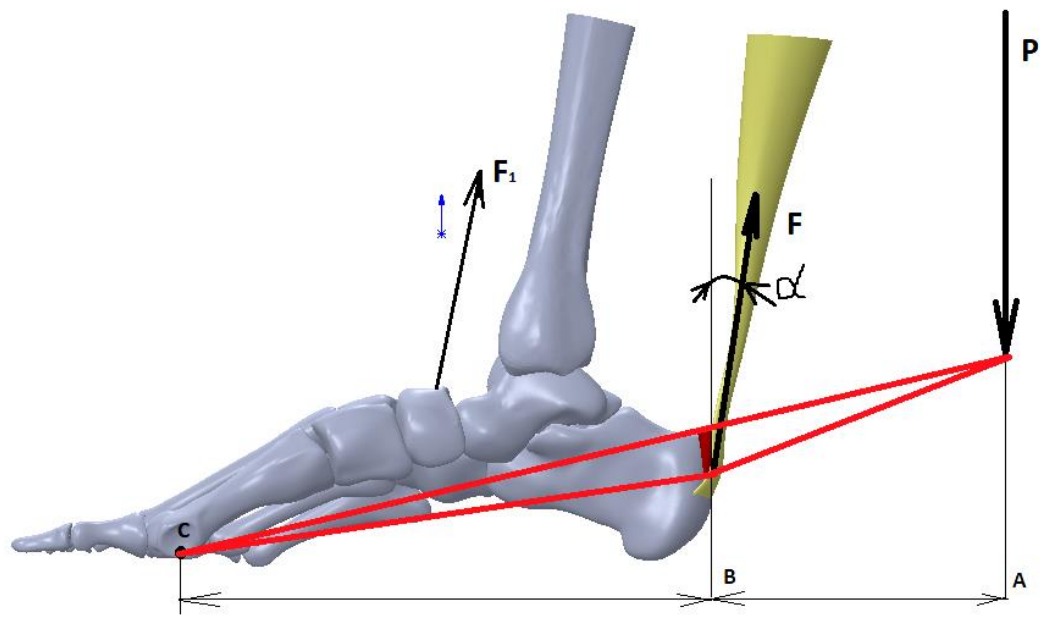

Fig. 2. Estimated 3D model at the position of the plantar flexion $-10^{\circ}$ 


$$
\sum M_{c}=0: F \cdot \sin \alpha \cdot C B-P \cdot C A=0 ;
$$

where $\alpha$ - the angle of inclination of the AT relative to the vertical axis; $\mathrm{P}$ - body weight $750 \mathrm{~N}(75 \mathrm{~kg}) ; \mathrm{F}$ - Achilles tendon tension force.

$$
F=\frac{P \cdot C \mathrm{~A}}{\sin \alpha \cdot C B}=459 \mathrm{H} ;
$$

- the force required to maintain the vertical position of the body in plantar flexion $-10^{\circ}$ of the foot.

But the value of force is divided into two components: the tension of the AT $65 \%(277 \mathrm{H})$ and the stabilizing force of the anterior muscle group 35\% $(182 \mathrm{H})$.

To achieve a back flexion of $+10^{\circ}$, the center of mass of the body is shifted forward by the distance of the AC as shown in Fig. 3. Therefore, to calculate the AT tension, this distance must be taken into account.

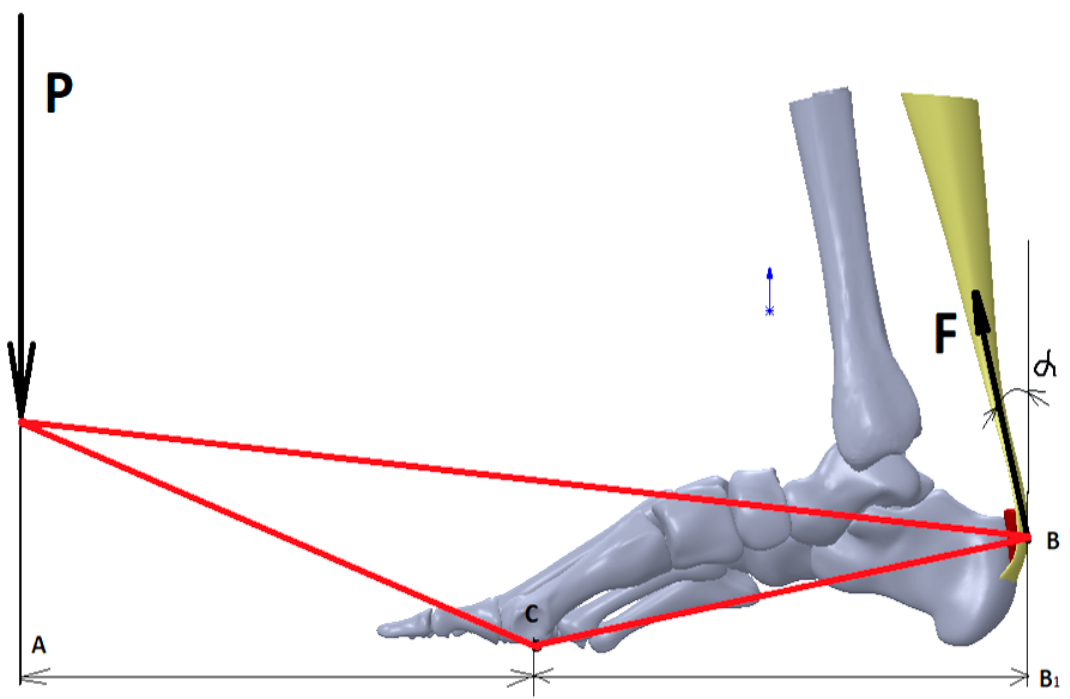

Fig. 3. 3D model in the position of the dorsal flexion $+10^{\circ}$ in the ankle

$$
\sum M_{c}=0: F \cdot \sin \alpha \cdot C B_{1}-P \cdot C A=0 ;
$$

where $\alpha$ - the angle of inclination of the AT relative to the vertical axis; $\mathrm{P}$ - body weight $750 \mathrm{~N}(75 \mathrm{~kg}) ; \mathrm{F}$ - Achilles tendon tension force. 


$$
F=\frac{P \cdot C A}{\sin \alpha \cdot C B_{1}}=1028 \mathrm{H} ;
$$

- the force required to hold the vertical position of the body when pushing the hind leg away from the ground (dorsal flexion $+10^{\circ}$ ).

Considering all of the above, we will use the following values of the AT loads to determine the SSS:

- for keeping the body in a standing position develops AT efforts in $458 \mathrm{H}$;

- to support the foot when approaching the ground (heel strike), the AT develops an effort of $277 \mathrm{H}$ (65\% of standing force) and $182 \mathrm{H}(35 \%)$ develops the front group of the lower leg muscles as stabilizers;

- to detach the foot from the ground (toe-off) and lift it to $10^{\circ}$ AT develops an effort of $1028 \mathrm{H}$.

Further calculations performed by finite element analysis (FEA), which allows to explore the evolution of the deformation process simulation model elements - bone, bursa and the tendon, with large nonlinear geometric and physical properties of materials and time variables external influences. For the purpose of calculating the SSS by the FEA, the simulation models were imported into the "ANSYS" (ANSYS, Inc., USA). The calculations used the following physical properties of biological tissues (table 1).

Table 1

Properties of model materials

\begin{tabular}{|l|c|c|}
\hline \multicolumn{1}{|c|}{ Material } & Young's module, Pa & Poisson's ratio \\
\hline Cortical bone & $17,6 \mathrm{e} 9$ & 0,3 \\
\hline Bursa & $5 \mathrm{e} 7$ & 0,45 \\
\hline Tendon & $4 \mathrm{e} 8$ & 0,45 \\
\hline
\end{tabular}

Three models were studied for each variant of the calculation - an intact model, a model with a RB and a model with Haglund syndrome for three positions in the ankle (Fig. 4).

In semiautomatic mode, finite element (FE) models were generated, which averaged 332906 nodes and 191538 elements (Fig. 5). To increase the accuracy of FEA, the mesh is compacted in the contact areas of the bursa and tendon elements. The FE grid is represented mainly by tetrahedral elements, the size of which on the basic model does not exceed $1 \mathrm{~mm}$, at the points of concentration of $0.1-0.5 \mathrm{~mm}$. 


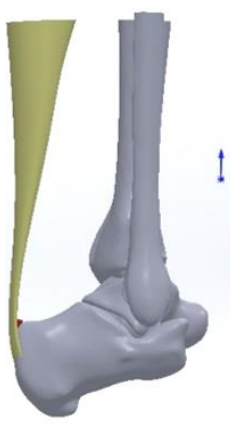

a)

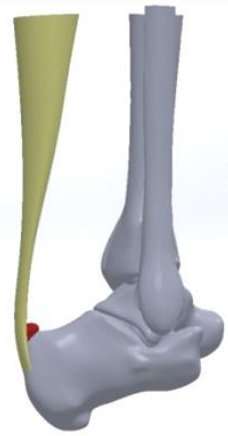

b)

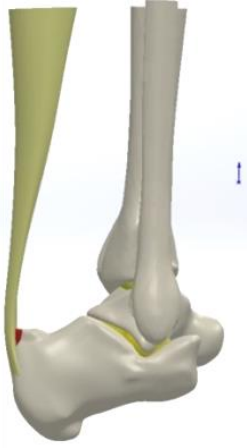

c)

Fig. 4. Simulation 3D models: intact model (a), model with RB (b) and model with Haglund syndrome (c)

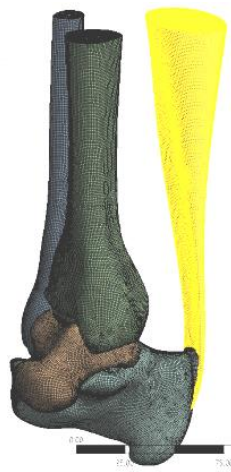

a)

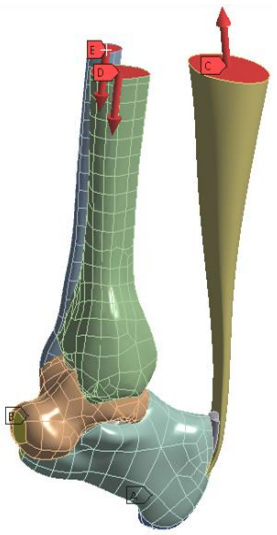

b)

Fig. 5. FE mesh (a) and boundary conditions (b), where A - rigid fixation of the plantar area of the calcanea, $B$ - restriction of movement on the axes with the possibility of rotation (to simulate a solid foot), $\mathrm{C}$ - tension force of the AT, D and E - body weight is applied to the tibia $(\mathbf{9 0 \%})$ and fibula $(10 \%)$

The key parameters for comparative analysis are the data obtained by calculating the stress (Mises) and strain intensity, as well as the total deformations, which were determined on all elements of the model. 


\section{Results and analysis}

SSS parameters of models in the neutral ankle position for each variant of the calculations - an intact model, a model with retrocalcaneal bursitis and a model with Haglund syndrome are presented in Fig. 6, Fig. 7, Fig. 8 and Table 2.

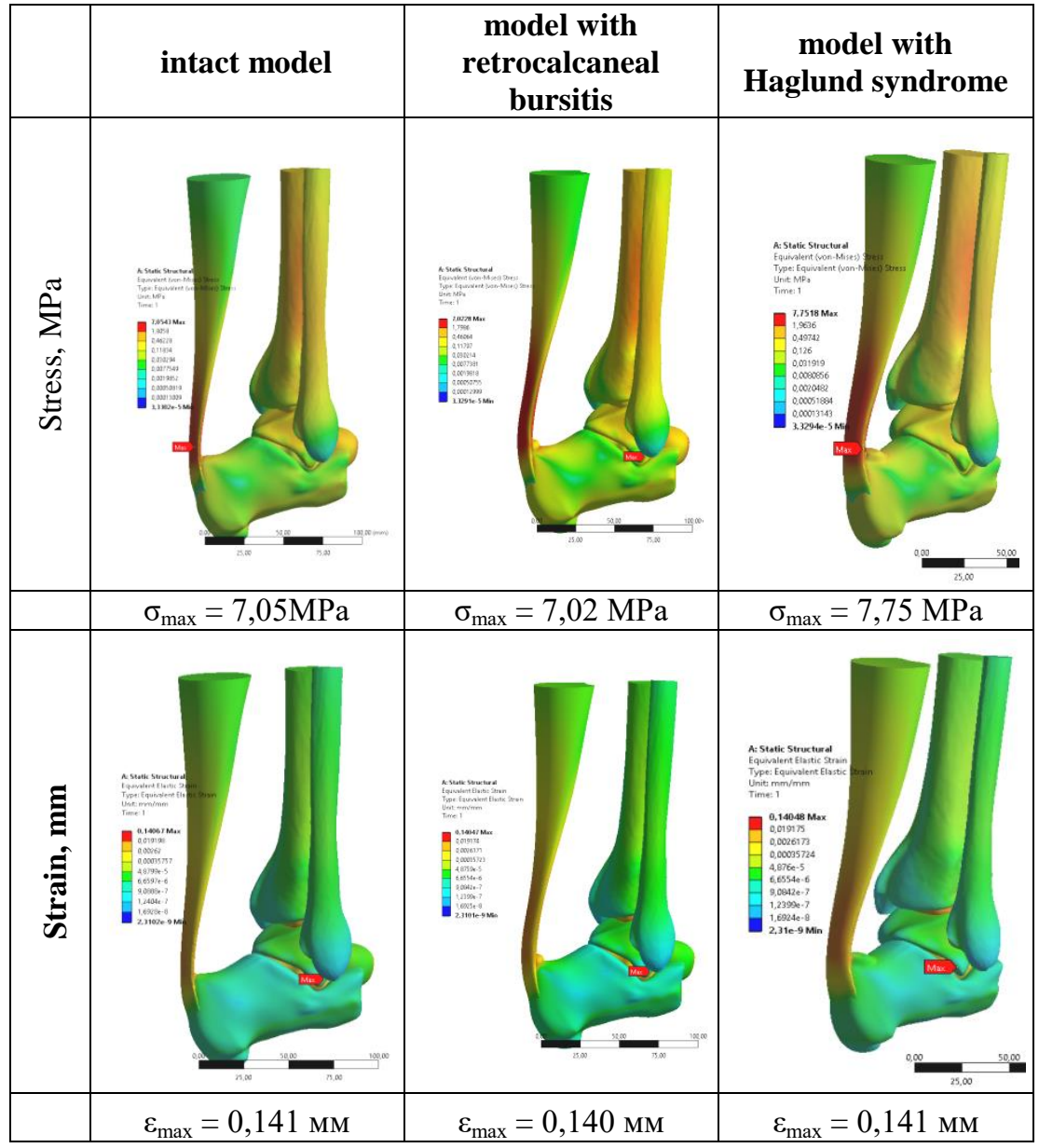

Fig. 6. SSS parameters of models in the neutral ankle position for each variant of the calculations - an intact model, a model with a bursitis and a model with Haglund syndrome 


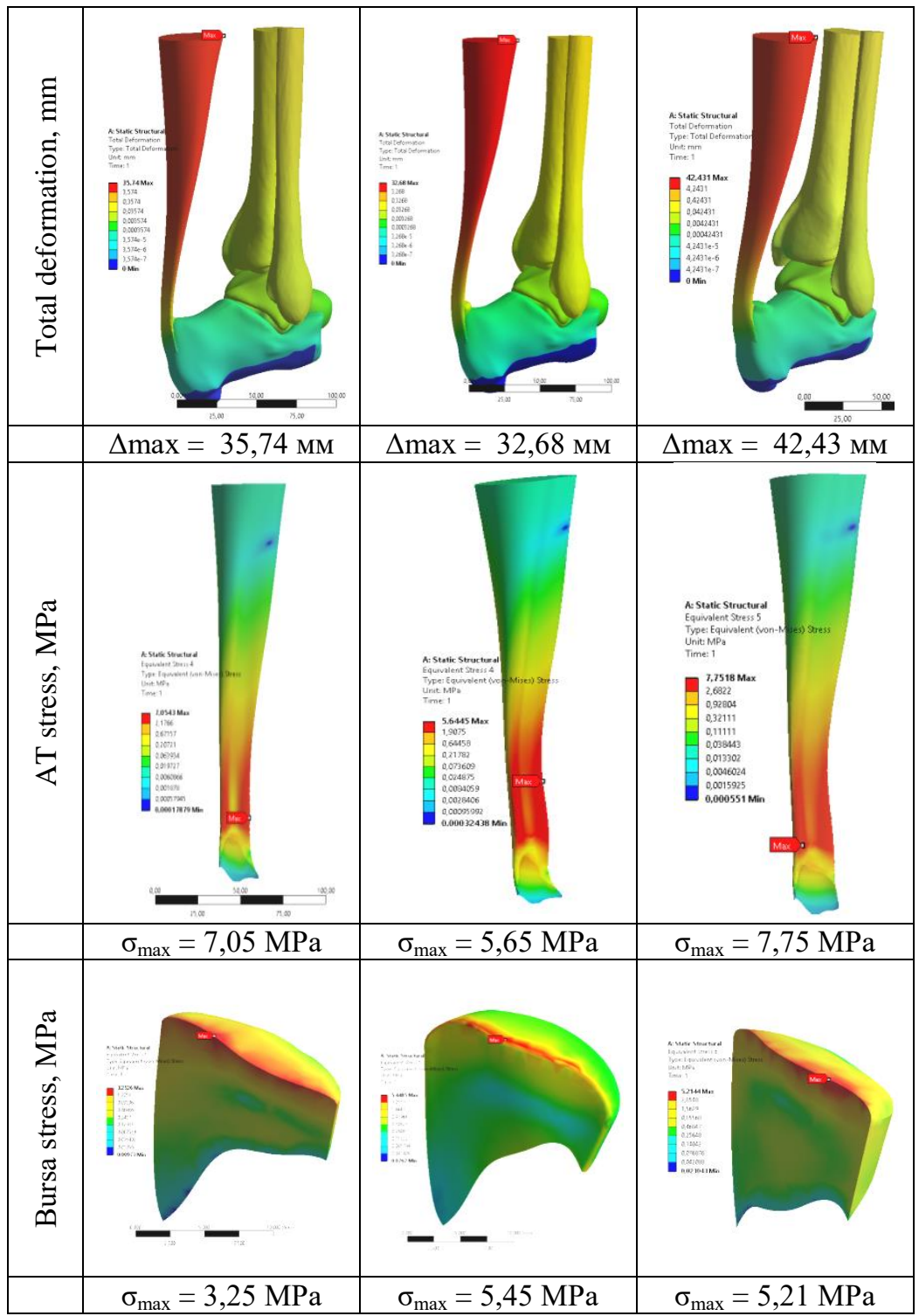

Fig. 7. SSS parameters of models in the neutral ankle position for each variant of the calculations - an intact model, a model with a bursitis and a model with Haglund syndrome 


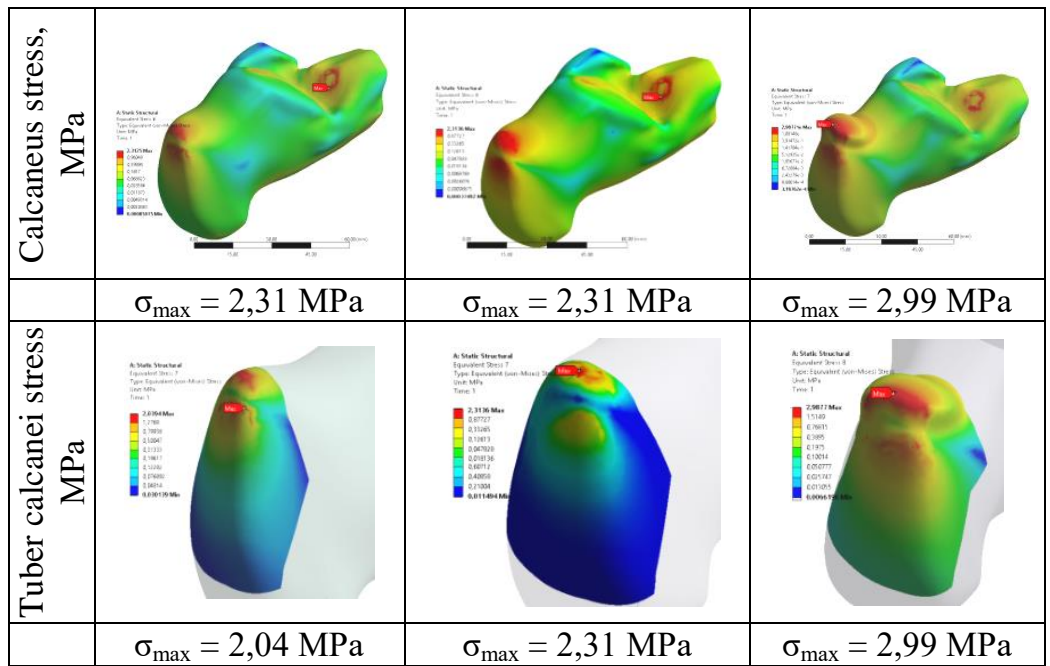

Fig. 8. SSS parameters of models in the neutral ankle position for each variant of the calculations - an intact model, a model with a bursitis and a model with Haglund syndrome

Table 2

Values of the SSS parameters for models in the neutral ankle position for each calculation option

\begin{tabular}{|l|c|c|c|}
\hline & Intact model & $\begin{array}{c}\text { Model with a } \\
\text { bursitis }\end{array}$ & $\begin{array}{c}\text { Model with } \\
\text { Haglund } \\
\text { syndrome }\end{array}$ \\
\hline Stress, MPa & 7,05 & 7,02 & 7,75 \\
\hline Strain, mm & 0,141 & 0,14 & 0,141 \\
\hline Total deformation, mm & 35,74 & 32,68 & 42,43 \\
\hline AT stress, MPa & 7,05 & 5,64 & 7,75 \\
\hline Bursa stress, MPa & 3,25 & 5,45 & 5,21 \\
\hline Calcaneus stress, MPa & 2,31 & 2,31 & 2,99 \\
\hline $\begin{array}{l}\text { Tuber calcanei stress, } \\
\text { MPa }\end{array}$ & 2,04 & 2,31 & 2,99 \\
\hline
\end{tabular}

It was determined that the stress values of the whole model in the intact model and the model with RB weren't practically different $-7.05 \mathrm{MPa}$ and $7.02 \mathrm{MPa}$ respectively. However, these parameter was higher by $10.0 \%$ in the model with Haglund syndrome and amounted to 7.75MPa. Strain of the model did not differ in all the studied models and amounted to $0.14 \mathrm{~mm}$. 
The maximum values of total deformations were expected on the calf muscle and in the intact model were amount to $35.74 \mathrm{~mm}$, in the model with bursitis $-32.68 \mathrm{~mm}$, in the model with Hagund syndrome $-42.43 \mathrm{~mm}$. In relation to the intact model, this value in the model with bursitis was less by $8.5 \%$ and more by $18.7 \%$ in the model with Hagund syndrome. To fix the body in a standing position, the calf muscle has to contract more in Haglund syndrome. We believe this is an additional factor leading to an overload of the AT-calf muscle.

We also investigated the maximum stress values for rear foot structures: $\mathrm{AT}$, retrocalcaneal bursa and the calcaneus.

The maximum value of AT stress was determined in the model with Haglund syndrome $-7.75 \mathrm{MPa}$, which is $10.0 \%$ higher than in the intact model (7.05MPa). It should be noted that in the intact model and the model with Haglund syndrome, the maximum streess were registered at the AT, while the stress at the AT in the model with a RB was $20.0 \%$ less (5.64 MPa) than in the intact model. We believe that this is due to the damping properties of the enlarged retrocalcaneal bursa, which effectively reduces the stress on the AT and distributes it evenly over the surface of the calcaneus. At the same time, there is a widening of the contact spot of the bursa and the tendon itself, which in our opinion is also important in the development of secondary changes of the tendon.

Investigating the value of bursa stress we obtained the expected results. Thus, the parameter was higher by $67.7 \%$ in the RB model (5.45 MPa) and $60.3 \%$ (5.21 MPa) in the model with Haglund syndrome compared to the intact model $(3.25 \mathrm{MPa})$. It is proved that the increase of the retrocalcaneal bursa is the leading pathogenetic factor of this deseases.

The calcaneus stress values were $29.4 \%$ higher in the Haglund syndrome model and were $2.99 \mathrm{MPa}$ versus $2.31 \mathrm{MPa}$ in the $\mathrm{RB}$ and intact model. It should be noted that, unlike the intact model, maximal stresses on the calcaneus in pathological models were concentrated on the tuber calcanei. The stress on the tuber calcanei are $13.2 \%$ higher in the model with RB and in the model with Haglund syndrome $46.5 \%$ higher than in the intact model. In our opinion, this indicates the unity of the system "AC-calcaneus" and the inability of the pathological process in the retrocalcaneal bursa without the absence of adaptive changes in other surrounding structures.

Summing up all the above results, it can be argued that, compared to the intact model, models with bursitis and Haglund syndrome are characterized by higher SSS values, which explains the development of secondary changes in AT and calcaneus.

A comparative analysis of the results of the SSS calculations for the models in the neutral ankle position for each variant of the study is presented in the diagram (Fig. 9). 


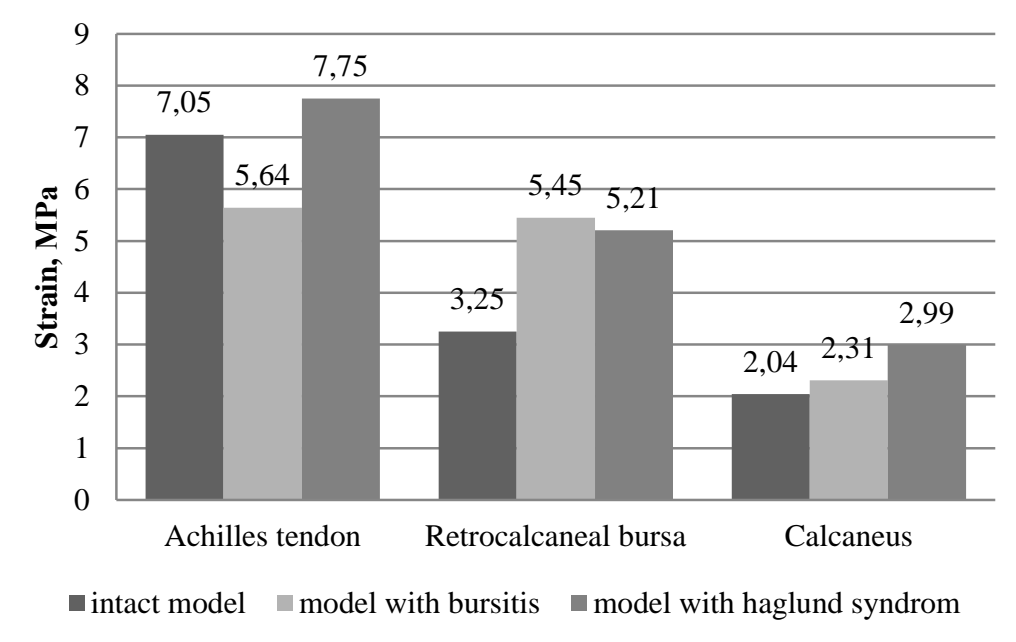

Fig. 9. Comparative analysis of the SSS values for models in the neutral ankle position for each study option

The results of the SSS models in dorsal flexion of the foot for each variant of the calculation - an intact model, a model with a bursitis and a model with Haglund syndrome are presented on Fig. 10, Fig. 11, Fig. 12 and Table 3 .

Table 3

Values of the SSS parameters for models in the dorsal flexion for each calculation option

\begin{tabular}{|l|c|c|c|}
\hline & $\begin{array}{c}\text { Intact } \\
\text { model }\end{array}$ & $\begin{array}{c}\text { Model with } \\
\text { a bursitis }\end{array}$ & $\begin{array}{c}\text { Model with } \\
\text { Haglund } \\
\text { syndrome }\end{array}$ \\
\hline Stress, MPa & 15,82 & 17,43 & 26,67 \\
\hline Strain, mm & 0,14 & 0,155 & 0,147 \\
\hline Total deformation, mm & 81,59 & 103,29 & 136,36 \\
\hline AT stress, MPa & 15,82 & 17,43 & 26,67 \\
\hline Bursa stress, MPa & 7,41 & 16,79 & 16,44 \\
\hline Calcaneus stress, MPa & 4,02 & 5,19 & 8,85 \\
\hline $\begin{array}{l}\text { Tuber calcanei stress, } \\
\text { MPa }\end{array}$ & 4,02 & 5,19 & 8,85 \\
\hline
\end{tabular}




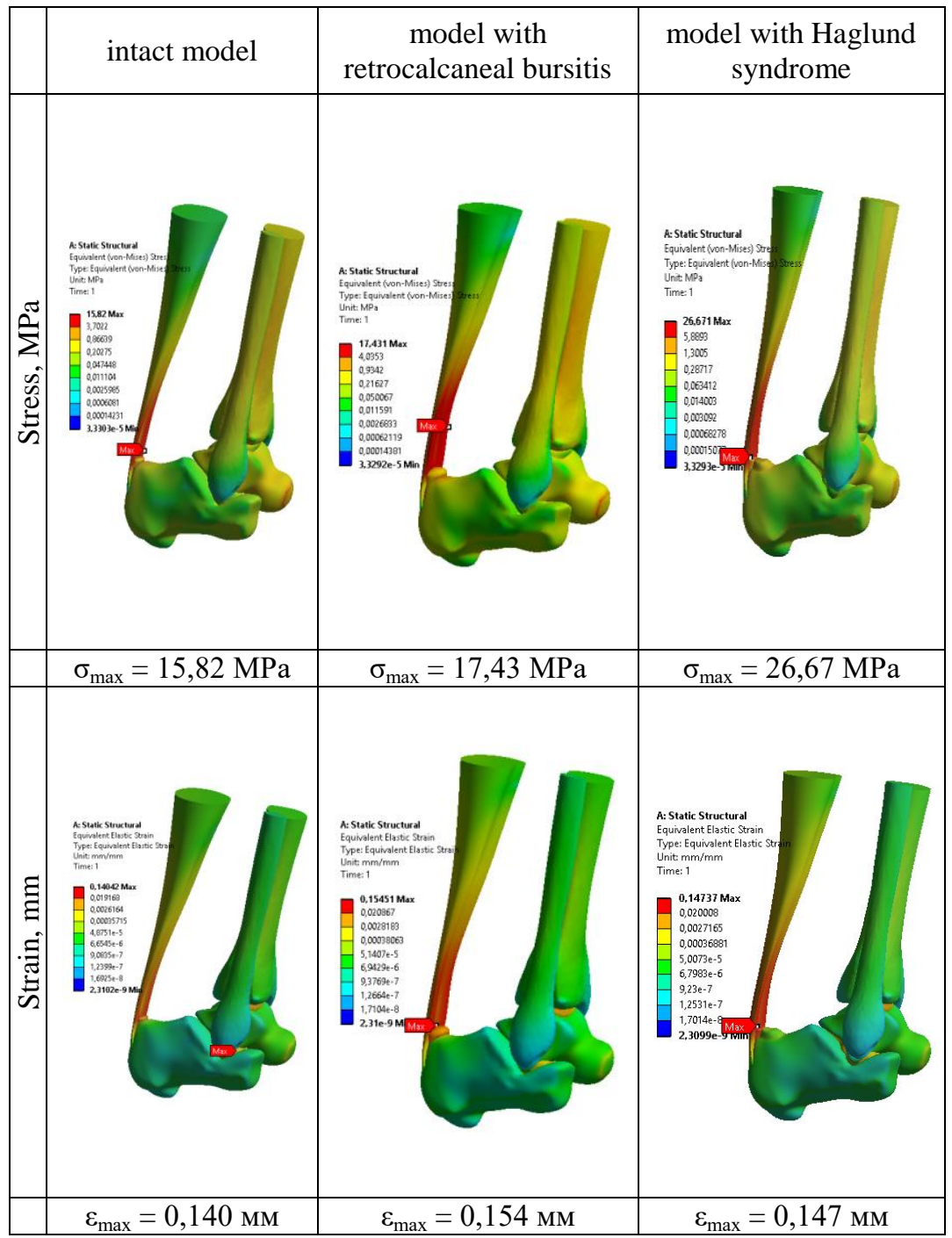

Fig. 10. SSS parameters of models in dorsal flexion of the ankle for each calculation option - an intact model, a model with a RB and a model with Haglund syndrome 


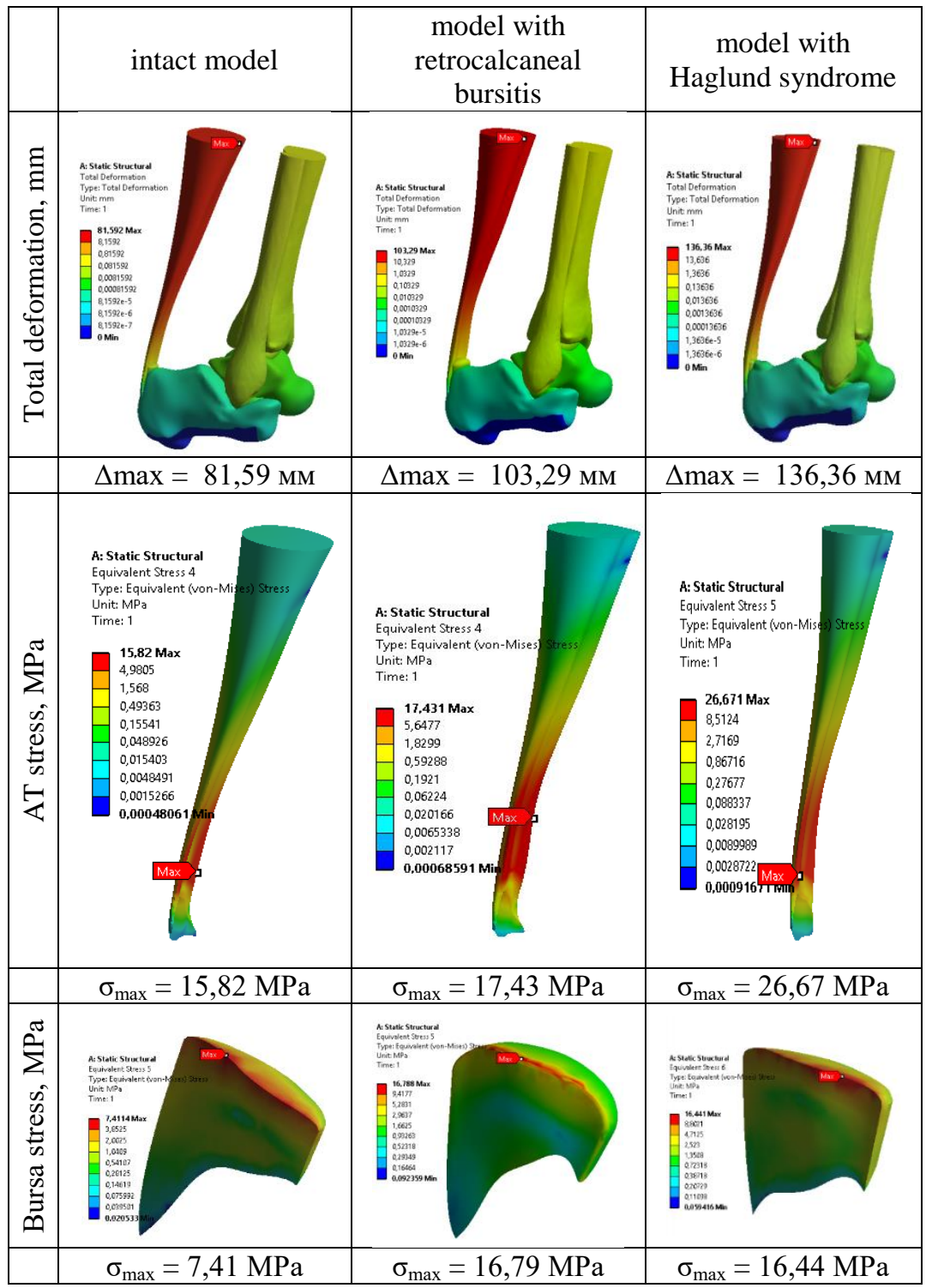

Fig. 11. SSS parameters of models in dorsal flexion of the ankle for each calculation option - an intact model, a model with a RB and a model with Haglund syndrome 


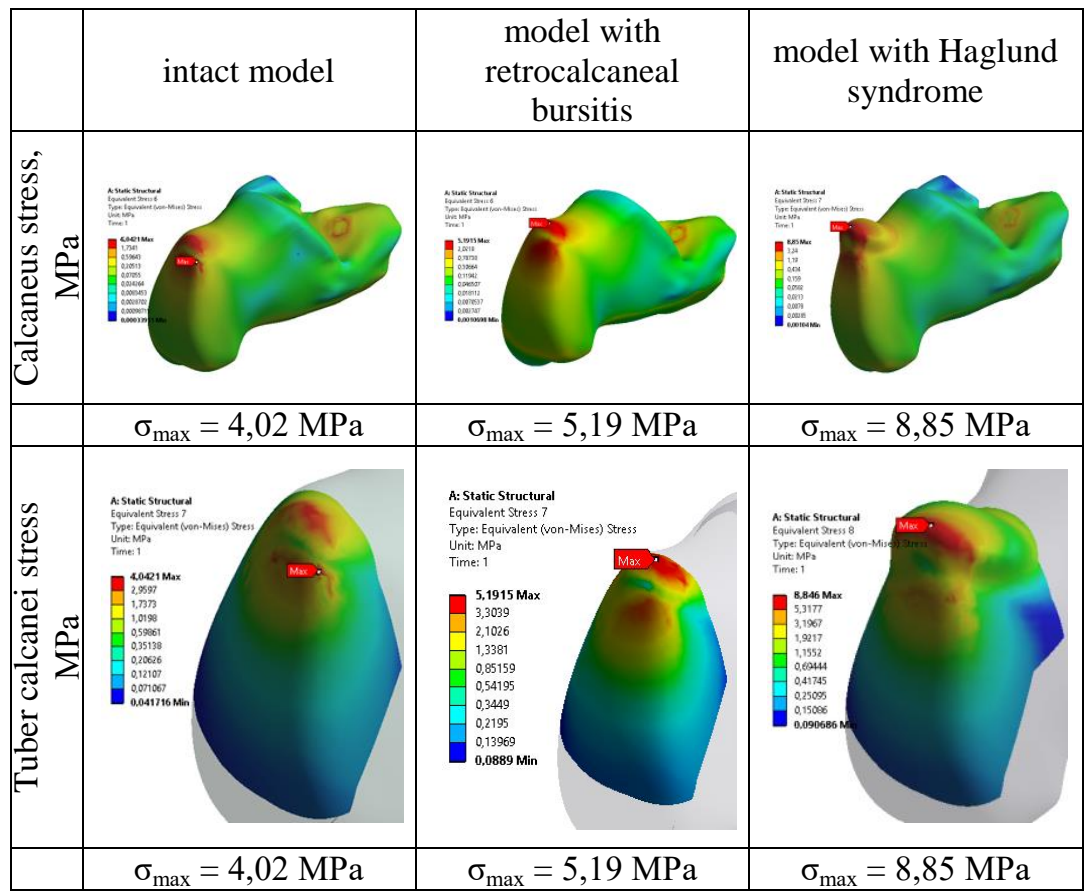

Fig. 12. SSS parameters of models in dorsal flexion of the ankle for each calculation option - an intact model, a model with a RB and a model with Haglund syndrome

In dorsal flexion, as we expected, on all anatomical structures of the models were the maximum values of SSS. So the highest stress values were localized on the AT. The intact model stress was $15.82 \mathrm{MPa}$, in the RB model with $17.43 \mathrm{MPa}$, and in the Haglund syndrome model, it was $26.67 \mathrm{MPa}$, which is $10.1 \%$ and $68.6 \%$ higher respectively. We believe that the concentration of maximum stresses on the AT in these diseases is the etiopathogenetic factor of concomitant secondary tendon diseases.

The strain values of the models were not significantly different in all three studied models and amounted to $0.14 \mathrm{~mm}$ for the intact model, $0.155 \mathrm{~mm}$ for the model with RB and $0.147 \mathrm{~mm}$ for the model with Haglund syndrome.

The study found that the maximum values of total deformations were localized on the calf muscle and amounted to $81.59 \mathrm{~mm}$ for the intact model, $103.29 \mathrm{~mm}$ for the model with bursitis and $136.36 \mathrm{~mm}$ for the model with Haglund syndrome, which was more respectively $26.6 \%$ and $67.1 \%$ compared to the intact model. It was found that in pathological models, to maintain the dorsal flexion of the foot, the calf muscle should be 
significantly reduced and carry additional load, which also plays a role in the development of secondary changes.

Also, in dorsal flexion, when AT inclination angle decreases, a significant increase in the stress on the enlarged bursa was observed. If in the intact model this parameter were $7.41 \mathrm{MPa}$, then in the bursitis model $16.79 \mathrm{MPa}(+126.6 \%)$, and in the model with Haglund syndrome $16.44 \mathrm{MPa}(+121.8 \%)$. In our opinion, such overloads cause further degenerative changes of the synovial membrane - its thickening and compaction, which in turn will affect the surrounding structures, such as the AT and the posterior upper parts of the calcaneus.

The highest stress values studied on the tuber calcanei were concentrated on its posterior-upper parts. If in the bursitis model the stress value was $5.19 \mathrm{MPa}$ and was $29.1 \%$ higher than in the intact model (4.02MPa), then in the model with Haglund syndrome the stress value was significantly higher $8.85 \mathrm{MPa}$, which is $120.1 \%$ more than in the intact model. However, in addition to the significant increase in tension in these part, it should be noted that in intact models, the maximum stress is localized more on the posterior surface of the tuber calcanei, on the anterior surface of the retrocalcaneal recess, whereas in pathological models the maximum stress was recorded on the upper surface of the posterior part. We believe that the formation of "Haglund deformity" is possible as a adaptive reaction of the body to the local overload of this anatomic area by an enlarged retrocalcaneal bursa. Normally, reactive reparative processes proceed as adaptive with normal physiological reactions. However, with pathological changes, they will reach the level of adaptive processes with structural changes.

Comparative analysis of SSS parameters for models in dorsal flexion of the ankle for each calculations option is presented in the diagram (Fig. 13).

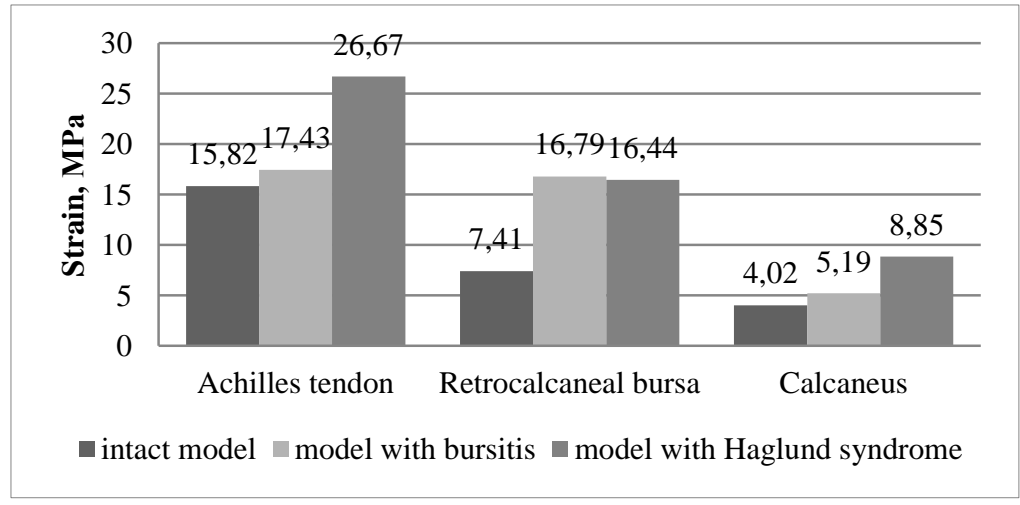

Fig. 13. Comparative analysis SSS parameters for models in the dorsal flexion of the ankle for each calculations option 
The values of the stress-strain state parameters of models in plantar flexion $-10^{\circ}$ - intact model, model with $\mathrm{RB}$ and model with Haglund syndrome are presented in Fig. 14, Fig. 15, Fig. 16 and Table 4.

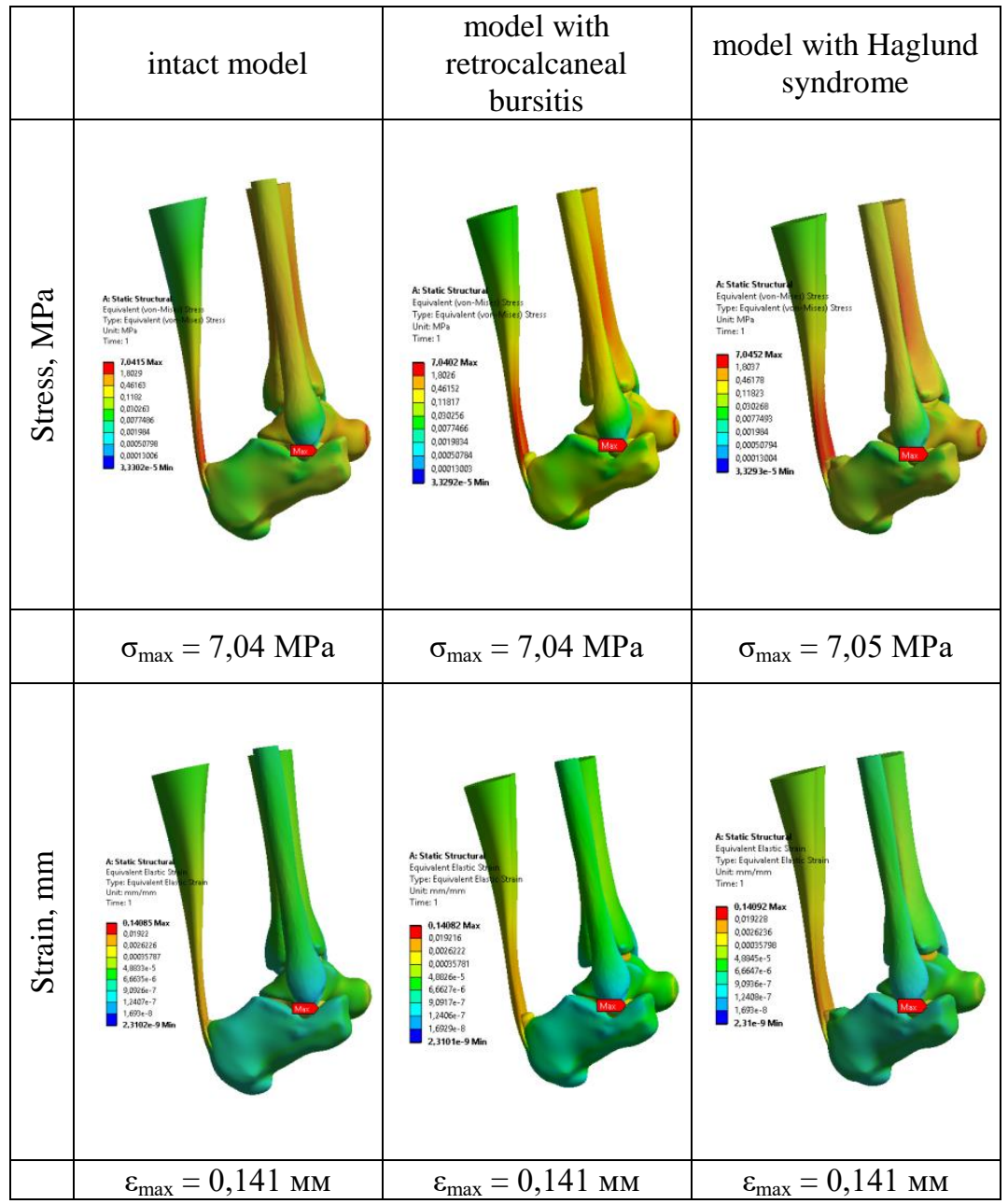

Fig. 14. SSS parameters of the studied models in the plantar flexion of the foot 


\begin{tabular}{|c|c|c|c|}
\hline & intact model & $\begin{array}{l}\text { model with } \\
\text { retrocalcaneal } \\
\text { bursitis }\end{array}$ & $\begin{array}{l}\text { model with Haglund } \\
\text { syndrome }\end{array}$ \\
\hline 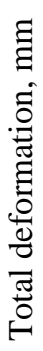 & 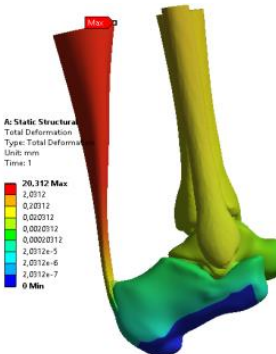 & 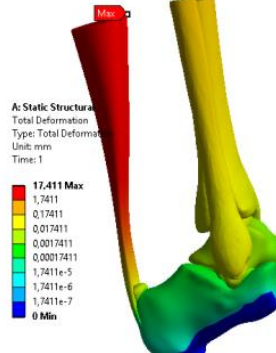 & 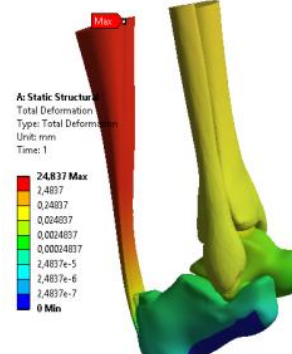 \\
\hline \multirow{3}{*}{ 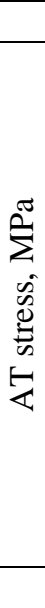 } & $\Delta \max =20,31 \mathrm{MM}$ & $\Delta \max =17,41 \mathrm{MM}$ & $\Delta \max =24,84 \mathrm{MM}$ \\
\hline & 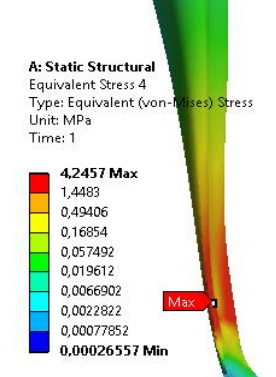 & 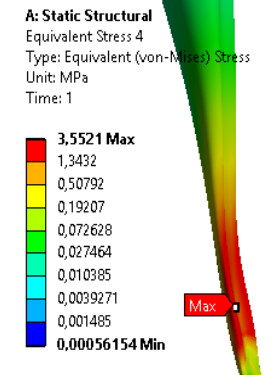 & $\begin{array}{l}\text { A: Static Structurad } \\
\text { Equivalent Stress } 5 \\
\text { Type: Equivalent (von-Mises) Stres } \\
\text { Unit: MPa } \\
\text { Time: } 1 \\
\\
\mathbf{5 , 8 7 0 9} \text { Max } \\
2,0793 \\
0,73645 \\
0,26083 \\
0,09238 \\
0,032719 \\
0,011588 \\
0,0041043 \\
0,0014536 \\
\mathbf{0 , 0 0 0 5 1 4 8 4} \text { Min } \\
\end{array}$ \\
\hline & $\sigma_{\max }=4,25 \mathrm{MPa}$ & $\sigma_{\max }=3,55 \mathrm{MPa}$ & $\sigma_{\max }=5,87 \mathrm{MPa}$ \\
\hline 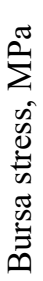 & 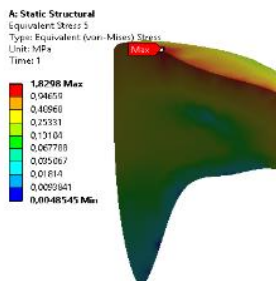 & 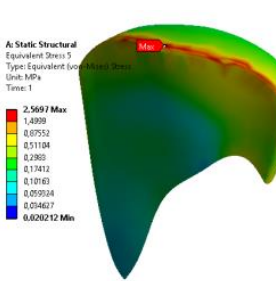 & 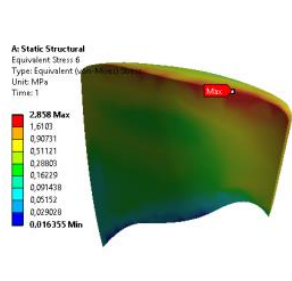 \\
\hline & $\sigma_{\max }=1,83 \mathrm{MPa}$ & $\sigma_{\max }=2,57 \mathrm{MPa}$ & $\sigma_{\max }=2,86 \mathrm{MPa}$ \\
\hline
\end{tabular}

Fig. 15. SSS parameters of the studied models in the plantar flexion of the foot 


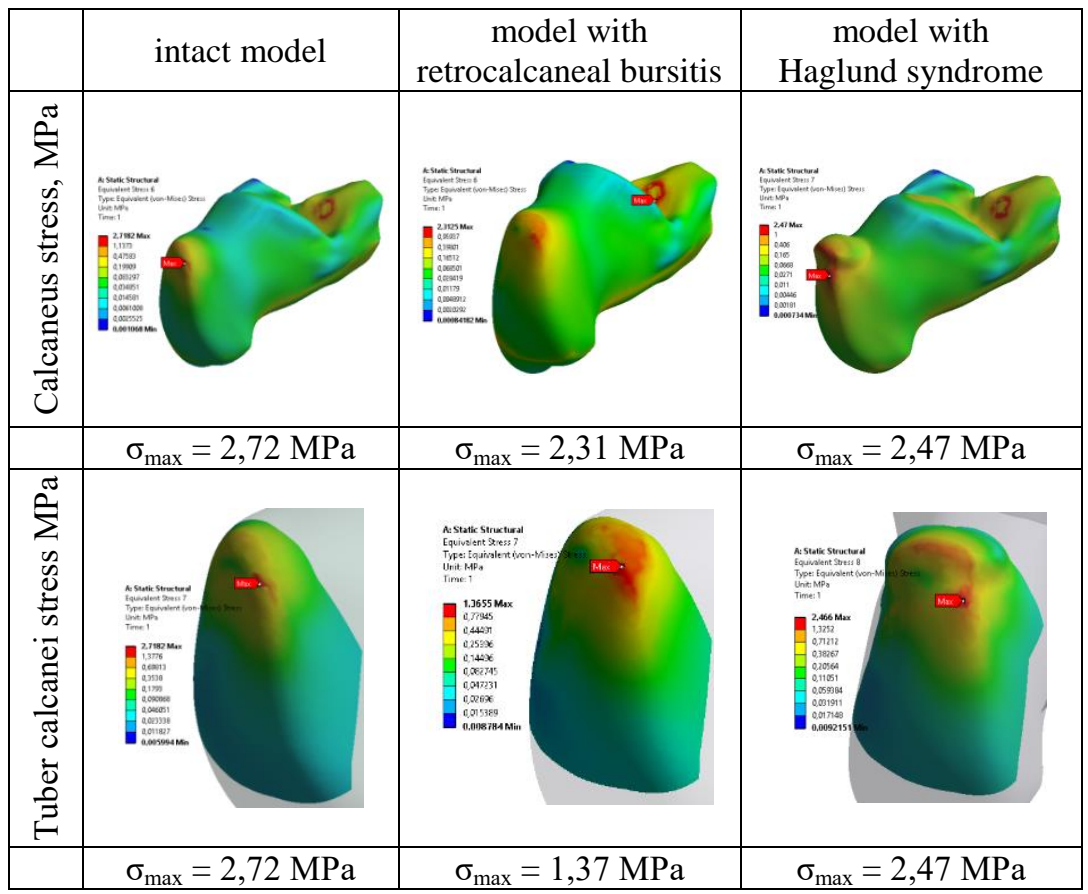

Fig. 16. SSS parameters of the studied models in the plantar flexion of the foot

Table 4

Values of the SSS parameters for models in the position of plantar flexion of the ankle for each calculation option

\begin{tabular}{|l|c|c|c|}
\hline & $\begin{array}{c}\text { Intact } \\
\text { model }\end{array}$ & $\begin{array}{c}\text { Model with } \\
\text { a bursitis }\end{array}$ & $\begin{array}{c}\text { Model with Haglund } \\
\text { syndrome }\end{array}$ \\
\hline Stress, MPa & 7,04 & 7,04 & 7,05 \\
\hline Strain, mm & 0,141 & 0,141 & 0,141 \\
\hline Total deformation, mm & 20,31 & 17,41 & 24,84 \\
\hline AT stress, MPa & 4,25 & 3,55 & 5,87 \\
\hline Bursa stress, MPa & 1,83 & 2,57 & 2,86 \\
\hline Calcaneus stress, MPa & 2,72 & 2,31 & 2,47 \\
\hline Tuber calcanei stress, MPa & 2,72 & 1,37 & 2,47 \\
\hline
\end{tabular}

In plantar flexion, the SSS of the rear foot structures in the studied models were lower than those in the neutral position or in dorsal flexion of the foot. This is due to both a decrease in the tensile strength of the AT and 
an increase in the size of the retrocalcaneal recess, the introduction of the Kager fat pad, and the lack of the retrocalcaneal bursa impingement.

Thus, the stress values of the whole model in all the tested models were equal 7.04 MPa. It should be noted that this stress was recorded on the ankle bone structures and not on the rear foot structures.

Strain values of the models did not differ for all three studied models and amounted to $0.141 \mathrm{~mm}$.

The maximum values of total deformations were recorded on the calf muscle and were $20.31 \mathrm{~mm}$ for the intact model, $17.41 \mathrm{~mm} \mathrm{(-14.2 \% )}$ for the bursitis model, and $24.84 \mathrm{~mm}(+22.3 \%)$ for the model with Haglund syndrome.

Similar results were obtained at the AT. Thus, the tendon stress in the intact model was 4.25 MPa, in the bursitis model - 3.55 MPa (-16.8\%) and in the model with Haglund syndrome $-5.87 \mathrm{MPa}(+38.1 \%)$.

It is found that the stress values on the bursa they were $40.4 \%$ higher in the bursitis model $(2.57 \mathrm{MPa})$ and $56.3 \%(2.86 \mathrm{MPa})$ in the model with Haglund syndrome compared to the intact model (1.83MPa).

The study calculated the stresses on the tuber calcani. In contrast to the previous values of this parameter in other positions of the foot on pathological models of tension was lower compared to the intact model. Thus, in the model with Haglund syndrome, the strain values was $2.47 \mathrm{MPa}$, and in the model with bursitis - only $1.37 \mathrm{MPa}$, which is $9.2 \%$ and $49.6 \%$ less than in the intact model $(2.72 \mathrm{MPa})$. In our opinion, the reduction of stress in pathological models is associated with a larger contact surface and a more uniform stress distribution on the calcaneus surface and the AT.

Comparative analysis values SSS parameters for models in plantar flexion of the ankle for each calculation option is presented in the diagram (Fig. 17).

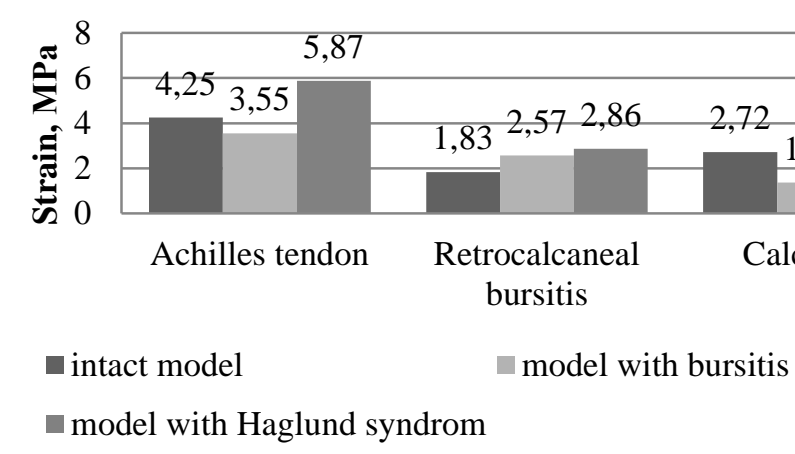

Fig. 17. Comparative analysis values SSS parameters for models in plantar flexion of the ankle for each calculation option 
In the study, we also analyzed the SSS values of the rear foot structures: $\mathrm{AT}$, the retrocalcaneal bursa, the calcaneus and the calf muscle. In our opinion, the these anatomical structures form a single biomechanical system, so its further study is key to understanding of the relationship between the components in normal and disease. The values and dynamics of strain at the AT are presented in Fig. 18.

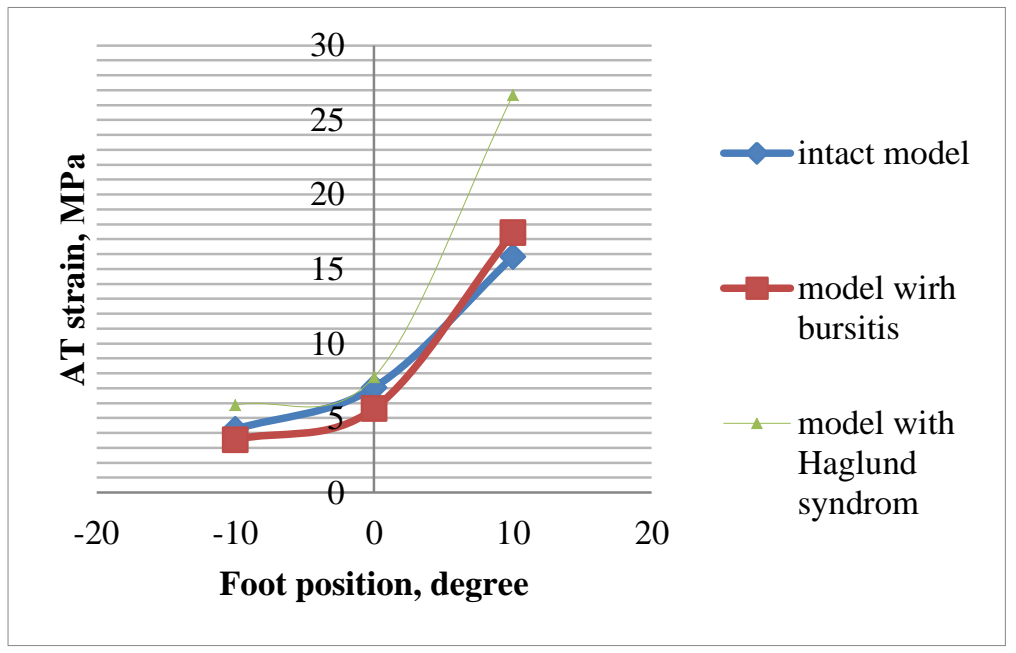

Fig. 18. Dynamics of strain values on the AT depending on the position of the foot for the all models

Analyzing the dynamics of AT stress values for the studied models, higher values are observed in the model with Haglund syndrome. The stress gain was $244.1 \%$. The same parameter in the model with bursitis was equal to $209,0 \%$, in intact models $-124,4 \%$.

The data obtained indicate the overload of the AT in patient with retrocalcaneal bursitis and Haglund syndrome. It should be noted that in the transition from the neutral position to the position of the dorsal flexion, the tension increases geometrically. Unlike pathological intact model shows a more linear increase.

However, it should be noted that the AT stress values in the RB model within $-10^{\circ}-0^{\circ}$ were less than in the intact model. We associate this with the damping function of the retrocalcaneal bursa. The synovial bursa more effectively distributes the stress from the AT by increasing the size.

The values and dynamics of the stree on the retrocalcaneal bursa are presented in Fig. 19. 


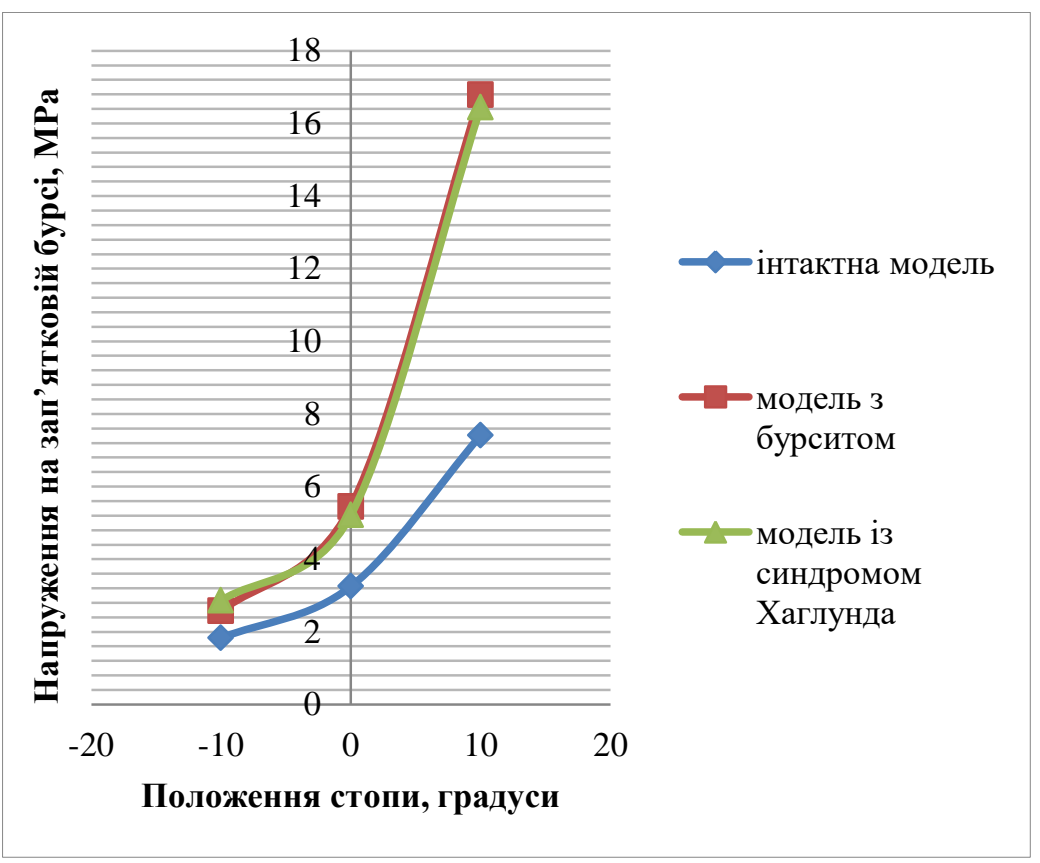

Fig. 19. Dynamics of stress values on the retrocalcaneal bursa, depending on the position of the foot for the studied models

Analyzing the dynamics of the bursa stress values, higher values on pathological models are noted. Thus, in the transition from the neutral position to the dorsal flexion position $\left(+10^{0}\right)$, the stress increase was $208.0 \%$ for the model with the bursitis and $215.5 \%$ for the model with Haglund syndrome. For the intact model, the increase of this parameter was only $128.0 \%$.

The data obtained indicate a significant overload of the synovial bursa. In our opinion, this can lead to degenerative changes in the synovial membrane - its thickening and compaction. In the clinical case, thickening synovial membrane of the bursa will have an impact not only on the disease course and on the effectiveness of treatment.

During the study, we investigated the maximum values of the SSS parameters at the AT insertion. This anatomic area directly contacts the retrocalcaneal bursa, which, in our opinion, can affect the pathogenesis of the disease.

The values and dynamics of strain on the tuber calcanei are presented on Fig. 20. 


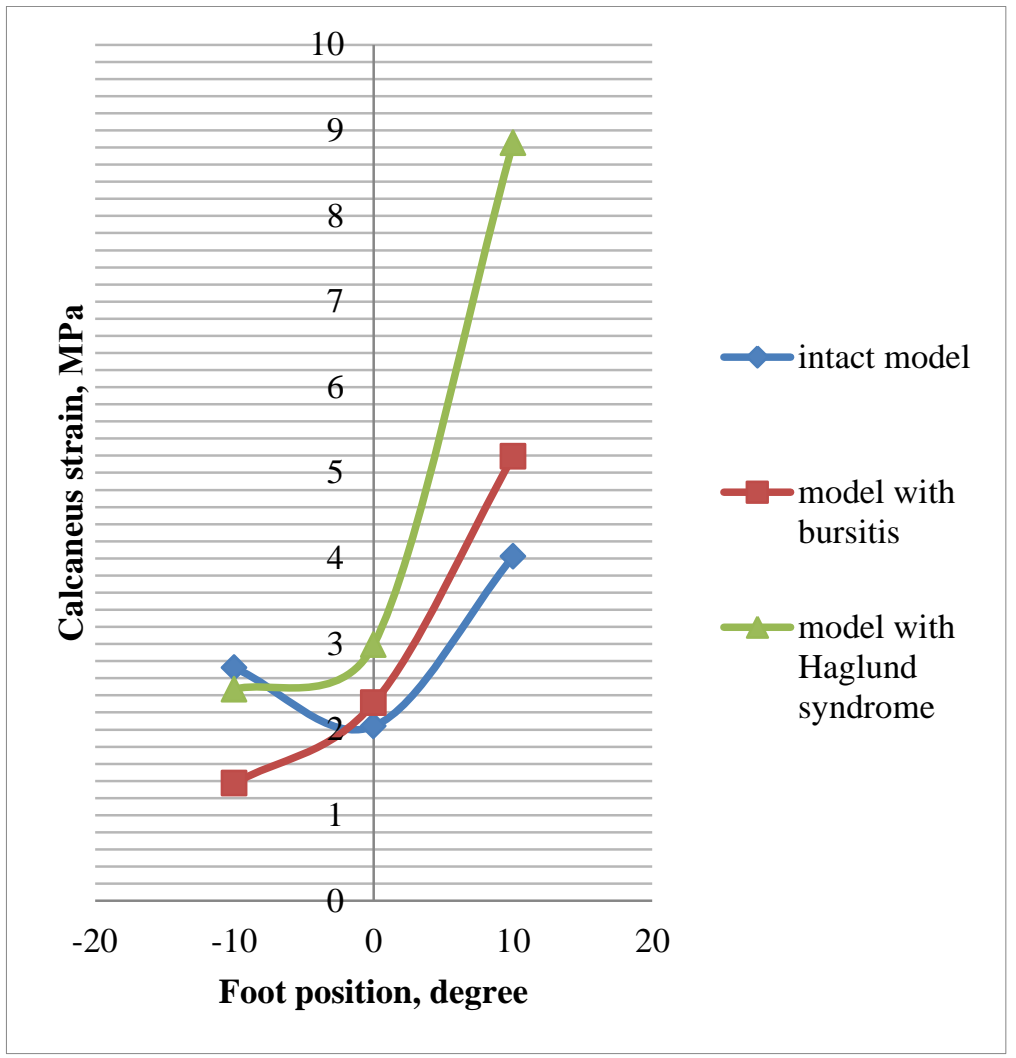

Fig. 20. Dynamics of stresses on the calcaneus depending on foot for the studied models

The study found that in the position of plantar flexion stress on the tuber calcanei in models with Haglund syndrome and RB was lower by $17.4 \%$ and $40.7 \%$, respectively, compared to the intact model. This is explained by the increase in the contact surface of the enlarged bursa with the calcaneus. However, already in the neutral position of the foot strain in pathological models was recorded more than in the intact model. When moving from the neutral position to the dorsal flexion, the stress on the calcaneus increased. Thus, in the model with RB, the increase in stress was $124.6 \%$, in the model with Haglund syndrome $-196.0 \%$, in the intact model was $97.0 \%$.

Maximum values of total deformations among all structures of the model were recorded on the calf muscle. The values and dynamics of total deformations are presented on Fig. 21. 

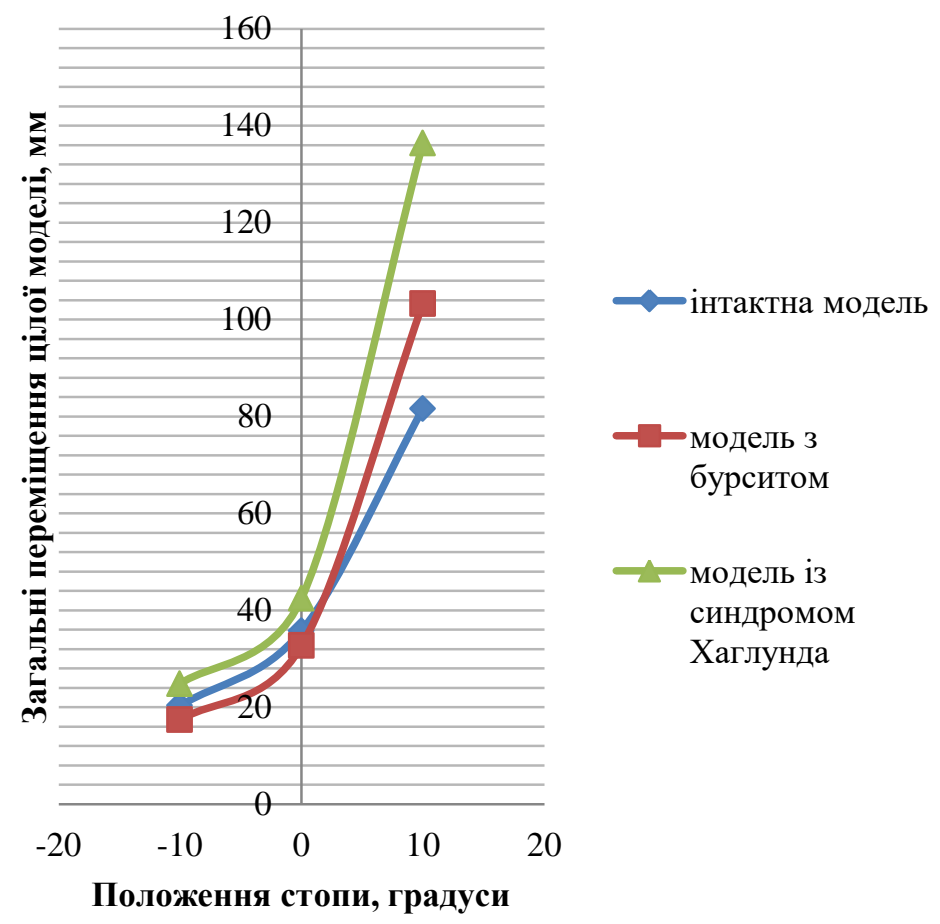

- модель 3

бурситом

$\sim$ модель із

синдромом

Хаглунда

Fig. 21. Dynamics of values of total deformations depending on the position of the foot for the studied models

The values of the total deformationss in plantar flexion in all models were lower compared to the similar results in the neutral position and in the dorsal flexion. However, in the model with Haglund syndrome, compared to the intact model, this parameter was $22.3 \%$ higher $(24.84 \mathrm{~mm}$ and $20.31 \mathrm{~mm}$ respectively) in the flexion position, $18.7 \%$ higher in the neutral position (42.43 $\mathrm{mm}$ and $35.74 \mathrm{~mm}$ respectively) and $67.1 \%$ higher $(136.36 \mathrm{~mm}$ and $81.59 \mathrm{~mm}$ respectively) in the dorsal flexion of the foot.

In contrast to the above data, the maximum values of total deformations of the calf muscle in the model with RB did not differ from the values obtained in the intact model $-35.68 \mathrm{~mm}$ and $35.74 \mathrm{~mm}$, respectively, and in the position of plantar flexion movement was less by $14.3 \%$ than in the intact model. However, in dorsal flexion of the foot, the values reached the maximum and equaled $103.29 \mathrm{~mm}$, which is $26.6 \%$ higher than the similar values of the intact model. 
In our opinion, an increase total deformations values indicates an overload of the calf muscle. The analysis of the results showed that in the model with Haglund syndrome, the load on the calf muscle is greater than in the intact model in the whole range of motion of the ankle. In the model with a RB, the dynamics are somewhat different - only in the dorsal flexion registers the load more than in the intact model.

\section{CONCLUSIONS}

All structures of the rear foot (AT, retrocalcaneal bursa, calcaneus) make up a single biomechanical system. Changes in the SSS of one part of the system lead to adaptive changes others and the whole system.

It is proved that the maximum stress concentrates on the AT; however, in the cases of RB and Haglund syndrome, the stress values were significantly higher than the normal values.

The damping function of the enlarged retrocalcaneal bursa has been proved by increasing the surface of contact with surrounding structures.

In our study were also identified features redistribution of stress on the tuber calcanei - in RB maximum values concentrates on posterior-superior part of the calcaneus (Haglund deformity). Normally, maximum stresses are localized on the posterior surface of the calcaneus - the anterior wall of the retrocalcaneal recess. And if in the case of Haglund syndrome this is explained by the enlargement of these parts of the calcaneus, then in the case of $\mathrm{RB}$ such redistribution of stress can lead to adaptive changes in the structure of the bone with the enlargement of these part and the formation of Haglund deformity. Hypothetically, this indicates that RB and Haglund syndrome can be different stages of one pathological process - the impingement of the retrocalcaneal bursa.

It has been established that overload is localized not only in the area of the heel hump, but also in the calf muscle, which expands the complexity of disorders in patient with RB and Haglund syndrome.

\section{SUMMARY}

In this study, a biomechanical relationship was found between the pathological process in retrocalcaneal bursitis or Haglund syndrome and secondary tendinopathy of the achilles tendon. We have developed the calculation diagram, created computer models and determined the values of the stress-strain state of the rear foot structures in the normal, with retrocalcaneal bursitis and with Haglund syndrome. It was found that the maximum stress values are concentrated on the achilles tendon, but in pathological models the stress values were significantly higher than normal in the whole range of motion of the foot. Also proved by the damping 
function of the retrocalcaneal bursa due to the uniform distribution of the load on the surface of the tendon and calcaneus. Normally, maximal stress on the calcaneus is localized on its posterior surface - on the anterior surface of the retrocalcaneal recess. In retrocalcaneal bursitis, maximum stress was recorded on the upper surface of the posterior sections of the calcaneus, which is hypothetical may indicate an association between these diseases. Haglund syndrome is marked by overloading of the calf muscle.

\section{REFERENCES}

1. Alfredson H., \& Spang C. Clinical presentation and surgical management of chronic Achilles tendon disorders - A retrospective observation on a set of consecutive patients being operated by the same orthopedic surgeon. Foot Ankle Surg. 2018 Dec. № 24(6). P. 490-494. doi: 10.1016/j.fas.2017.05.011.

2. Haglund P. Beitrag zur Klinik der Achillessehne. Zeitschr Orthop Chir. 1928. № 49. P. 49-58.

3. Irwin T.A. Current Concepts Review: Insertional Achilles Tendinopathy. Foot \& Ankle International. 2010. № 31(10). P. 933-939. doi: 10.3113/fai.2010.0933.

4. Karjalainen P.T., Soila K., Aronen H.J. [et al.] MR Imaging of Overuse Injuries of the Achilles Tendon. American Journal of Roentgenology. 2000. № 175(1). P. 251-260. doi:10.2214/ajr.175.1.1750251.

5. Reinherz R.P., Smith B.A., Henning K.E. Understanding the pathologic Haglund's deformity. J Foot Surg. 1990. № 29. P. 432-435.

Information about authors: Herasimyuk B. S.,

Graduate Student of the Department of Orthopedics and Traumatology № 1

Shupyk National Medical Academy of Postgraduate Education 9, Dorohozhytska str., Kyiv, 04112, Ukraine

Lazarev I. A., Candidate of Medical Sciences, Associate Professor of the Department of Orthopedics and Traumatology № 1

Shupyk National Medical Academy of Postgraduate Education 9, Dorohozhytska str., Kyiv, 04112, Ukraine 